\title{
Giovanna Angeli, Le strade della fortuna. Da Marie de France a François Villon
}

\section{Walter Meliga}

\section{(2) OpenEdition}

1 Journals

\section{Edizione digitale}

URL: http://journals.openedition.org/studifrancesi/27143

DOI: 10.4000/studifrancesi.27143

ISSN: 2421-5856

\section{Editore}

Rosenberg \& Sellier

\section{Edizione cartacea}

Data di pubblicazione: 31 décembre 2006

Paginazione: 571

ISSN: 0039-2944

\section{Notizia bibliografica digitale}

Walter Meliga, «Giovanna Angeli, Le strade della fortuna. Da Marie de France a François Villon », Studi Francesi [Online], 150 (L | III) | 2006, online dal 30 novembre 2015, consultato il 08 novembre 2020. URL : http://journals.openedition.org/studifrancesi/27143 ; DOI : https://doi.org/10.4000/ studifrancesi.27143

\section{Questo documento è stato generato automaticamente il 8 novembre 2020.}

\section{(c) (1)}

Studi Francesi è distribuita con Licenza Creative Commons Attribuzione - Non commerciale - Non opere derivate 4.0 Internazionale. 


\title{
Giovanna Angeli, Le strade della fortuna. Da Marie de France a François Villon
}

\author{
Walter Meliga
}

\section{NOTIZIA}

GiovanNa ANGel, Le strade della fortuna. Da Marie de France a François Villon, Pisa, Pacini Editore («Studi di Letterature Moderne e Comparate», 10), 2003, pp. 245.

1 Il volume raccoglie contributi già pubblicati (dal 1985 al 2001), ma «parzialmente rielaborati e aggiornati» (p. 8) per la presente raccolta, e si divide in quattro parti, dedicate rispettivamente alla cortesia, al riso, al destino e alla sventura. La parte della cortesia comprende tre lavori su Maria di Francia e altri autori della letteratura cortese (i trovatori, Chrétien de Troyes) e uno sulla misoginia e il rapporto fra gli sposi nella letteratura. Alla fatrasie e al suo codice espressivo chiuso sono dedicati i tre capitoli della parte sul riso, dove sono anche indagate le immagini bizzarre, di ispirazione fatrasica, disegnate sui margini dei manoscritti. Nella parte dedicata al destino unica figura è Christine de Pizan e la sua concezione della donna e della povertà. Infine, la parte della sventura raccoglie tre interventi su François Villon e la sua contestazione delle favole consolatrici della sfortuna e delle disgrazie umane. 